\title{
The Unmet Need for Clinical Guidelines on the Management of Patients with Plaque Psoriasis in Africa and the Middle East
}

This article was published in the following Dove Press journal: Psoriasis: Targets and Therapy

\author{
Martin Steinhoff ${ }^{1,2}$ \\ Alfred F Ammoury (D) ${ }^{3}$ \\ Haytham Mohamed Ahmed (iD ${ }^{4}$ \\ Mohamed Fathy Soliman \\ Gamal $^{4}$ \\ Mahira H El Sayed ${ }^{5}$ \\ 'Department of Dermatology and \\ Venereology, and HMC Translational \\ Research Institute, Hamad Medical \\ Corporation, Qatar University, and Weill \\ Cornell Medical College-Qatar, Doha, \\ Qatar; ${ }^{2}$ Department of Dermatology, \\ Weill Cornell University, New York, NY, \\ USA; ${ }^{3}$ Dermatology Division, Saint \\ George Hospital University Medical \\ Center, Beirut, Lebanon; ${ }^{4}$ Pfizer \\ Biopharmaceutical Group, Emerging \\ Markets, Dubai, United Arab Emirates; \\ ${ }^{5}$ Department of Dermatology and \\ Venereology, Ain Shams University, \\ Cairo, Egypt
}

Purpose: Dermatologists practicing in African and Middle Eastern countries face numerous challenges when managing patients with plaque psoriasis, especially those with disease in a difficult-to-treat anatomic area or those who are a pediatric, geriatric, or pregnant patient. The publication of comprehensive, up-to-date, region-specific clinical guidelines may help to address some of these challenges and improve outcomes. We conducted a literature review to identify recent guidelines and other publications describing patients with plaque psoriasis in Africa and the Middle East.

Patients and Methods: An online literature search of the PubMed database was conducted to identify publications reporting clinical guidelines and research studies on plaque psoriasis. The search included all articles published from January 2008 to March 2020 inclusive. The titles and abstracts of all search results were screened by a reader to identify those that described patients in Africa or the Middle East.

Results: A total of 145 publications were identified by the literature search and screened by a reader. There were 10 publications that described patients in Africa or the Middle East: 4 research articles, 3 reviews, 2 guidelines, and 1 case study. The 2010 guidelines from South Africa made recommendations for treating plaque psoriasis of varying severity, although without specific recommendations for difficult-to-treat anatomic areas or pediatric, geriatric, or pregnant patients. The 2014 guideline on biologics from Saudi Arabia included recommendations for the use of these agents in patients with plaque psoriasis, including difficult-to-treat anatomic areas and pediatric patients (TNF inhibitors only), but provided no recommendations for pregnant or geriatric patients.

Conclusion: There is an urgent unmet need for comprehensive clinical guidelines on the management of patients with plaque psoriasis in Africa and the Middle East. Region-specific studies on the epidemiology, burden of disease, and the safety and effectiveness of newer pharmacotherapies are needed to support the development of such guidelines.

Keywords: geriatrics, guidelines, pediatrics, pregnancy, psoriasis, unmet needs

\section{Plain Language Summary}

Guidelines that recommend how medical conditions should be managed by physicians are regularly published by learned societies so that health care services remain informed by the latest evidence from clinical studies. Such guidelines can vary from region to region and be influenced by the specific circumstances present within each. The prevalence of plaque psoriasis in African and Middle Eastern countries is believed to be similar to that observed in Western countries (approximately 1-3\% of the general population), but dermatologists practicing in African or Middle Eastern countries tend to rely on guidelines published by

Correspondence: Martin Steinhoff Department of Dermatology and Venereology, Hamad Medical Corporation, Doha, Qatar

Tel +97444395101

Fax +97444394727

Email martin_steinhoff@web.de
Psoriasis: Targets and Therapy 2020:10 23-28 
North American or European societies because of an apparent lack of regional guidelines. Prof. Steinhoff and his co-authors from Africa and the Middle East conducted an online literature search covering the previous 12 years in order to assess the availability of regional data and guidelines. Their results show that only 2 sets of guidelines on plaque psoriasis were published in the Africa and Middle East region during this 12-year period, and there were only 8 other articles published during this time. The authors therefore concluded that there is an urgent unmet need for up-to-date, region-specific guidelines on the management of patients with plaque psoriasis in Africa and the Middle East, and that more regional studies are required in order to support this effort.

\section{Introduction}

Plaque psoriasis is a relatively common, chronic autoimmune disease characterized by the appearance of scaly, erythematous plaques on the surface of the skin. These plaques are caused by the hyperproliferation of epidermal tissue in response to a proinflammatory milieu established by the extensive infiltration of the dermis and epidermis by dendritic cells, T cells, macrophages, and neutrophils. ${ }^{1,2}$ The disease has been shown to have a significant impact on the quality of life of those affected and imposes a considerable economic burden on individual patients and communities. $^{3-8}$

Dermatologists practicing in African and Middle Eastern countries face numerous challenges when managing patients with plaque psoriasis, especially those with disease in a difficult-to-treat anatomic area or those who are a pediatric, geriatric, or pregnant patient. For example, health care resources in some countries can be extremely limited and this may be combined with a general lack of awareness of the condition among patients, their families, policy makers, and non-specialist health care professionals who can confuse plaque psoriasis with other dermatologic conditions. In such resource-limited settings, the treatment of plaque psoriasis must frequently compete for government or state funding that is often directed towards other chronic diseases such as cancer, cardiovascular disease, and renal failure. In order for the clinical management of plaque psoriasis to be allocated a larger share of the current health care budgets available in the Africa and Middle East region, the impact of treatment needs to be discussed not only in terms of its potential to improve the quality of life of individual patients but also in terms of its potential to mitigate the long-term costs associated with chronic disability.
Published data suggest that the prevalence of plaque psoriasis in African and Middle Eastern countries is at least as high as that observed in Western countries, which report a prevalence of approximately $1-3 \%$ in the general white population. ${ }^{8-14}$ Despite this similarity in prevalence, there is an apparent lack of regional and national guidelines on how plaque psoriasis should be managed in African and Middle Eastern countries. In general, many physicians and health care providers in the region follow the clinical guidelines published by North American or European institutions, such as the American Academy of Dermatologists or the European Academy of Dermatology and Venereology. 8,15-19 Providing physicians in African and Middle Eastern countries with comprehensive, up-to-date, and region-specific guidelines that consider the newer pharmacotherapies available, as well as patient education and shared decisionmaking, should help to improve awareness and, most importantly, improve outcomes for patients and health care systems. The aim of the present study was to identify recently published articles on the management of patients with plaque psoriasis in Africa and the Middle East as a basis for further discussion on the development of new guidelines.

\section{Patients and Methods}

An online literature search of the PubMed database was conducted in April 2020 and included all articles published between January 2008 and March 2020 inclusive. Relevant publications were identified by using the following terms and tags: guideline[TI] AND psoriasis[TIAB]; difficult[TI] AND psoriasis[TIAB]; middle[TI] AND psoriasis[TIAB]; pregnant[TI] OR pregnancy[TI] AND psoriasis[TIAB]; geriatric[TI] OR elderly[TI] AND psoriasis[TIAB]; and pediatric[TI] OR childhood[TI] AND difficult[TIAB] AND psoriasis[TIAB]. Abstracts of all publications returned by the search terms were subsequently screened by a reader to identify those that described patients in Africa or the Middle East.

\section{Results}

The literature search returned a total of 145 publications and 10 of these described patients in Africa or the Middle East. Of these 10 publications, there were 4 research articles (Table 1), ${ }^{20-23} 3$ reviews (Table 2), ${ }^{8,24,25} 2$ guidelines ( 1 from South Africa in 2010 and 1 from Saudi Arabia in 2014; Table 3), ${ }^{26,27}$ and 1 case study (published in Hebrew). ${ }^{28}$ Two of the 4 research articles described non-interventional studies and 2 reported data from studies on the safety and efficacy of phototherapy ( 1 in patients 
Table I Research Articles Describing Patients with Plaque Psoriasis in Africa and the Middle East Published from January 2008 to March 2020

\begin{tabular}{|l|l|l|l|}
\hline Publication & Country & $\begin{array}{l}\text { Patient } \\
\text { Population }\end{array}$ & Study Type \\
\hline $\begin{array}{l}\text { Al-Mutairi } \\
\text { et al } \\
(2010)^{20}\end{array}$ & Kuwait & Adults (N=1835) & $\begin{array}{l}\text { Non- } \\
\text { interventional } \\
\text { (case-control) }\end{array}$ \\
\hline $\begin{array}{l}\text { Al-Mutairi N } \\
\text { and Al- } \\
\text { Haddad } \\
\text { A (20I3) }\end{array}$ & Kuwait & $\begin{array}{l}\text { Adults with localized } \\
\text { psoriasis of the scalp } \\
\text { or palmoplantar } \\
\text { areas }(\mathrm{N}=41)\end{array}$ & $\begin{array}{l}\text { Interventional } \\
\text { (phototherapy) }\end{array}$ \\
\hline $\begin{array}{l}\text { Kassi et al } \\
(2016)^{22}\end{array}$ & Coast & $\begin{array}{l}\text { Geriatric }(\geq 60 \\
\text { years) }(\mathrm{N}=47)\end{array}$ & $\begin{array}{l}\text { Non- } \\
\text { interventional } \\
\text { (cross-sectional) }\end{array}$ \\
\hline $\begin{array}{l}\text { Bulur et al } \\
(2018)^{23}\end{array}$ & Turkey & $\begin{array}{l}\text { Geriatric }(\geq 65 \\
\text { years) }(\mathrm{N}=95)\end{array}$ & $\begin{array}{l}\text { Interventional } \\
\text { (phototherapy) }\end{array}$ \\
\hline
\end{tabular}

Table 2 Review Articles Describing Patients with Plaque Psoriasis in Africa and the Middle East Published from January 2008 to March 2020

\begin{tabular}{|l|l|}
\hline Publication & Focus of Review \\
\hline Abdulghani et al (20II) ${ }^{24}$ & $\begin{array}{l}\text { Description of contemporary practice, } \\
\text { unmet needs, and the challenges faced by } \\
\text { dermatologists in Africa and the Middle East }\end{array}$ \\
\hline $\begin{array}{l}\text { Tavakolpour S and } \\
\text { Rahimzadeh G (2016) }\end{array}$ & $\begin{array}{l}\text { Discussion of the potential for therapeutic } \\
\text { immunomodulation in pregnant women } \\
\text { with autoimmune disease }\end{array}$ \\
\hline Al Hammadi et al (2017) & $\begin{array}{l}\text { Expert opinion on best practice } \\
\text { regarding the use of biologics in patients } \\
\text { with moderate-to-severe psoriasis in } \\
\text { Africa and the Middle East }\end{array}$ \\
\hline
\end{tabular}

with plaque psoriasis localized to the scalp or palmoplantar areas and 1 in patients $\geq 65$ years of age). Of the 3 review articles, 1 addressed the general management of plaque psoriasis in the region, 1 addressed the possibility of modulating immune responses in pregnant women with autoimmune diseases, and 1 addressed the use of biologics in the treatment of moderate-to-severe plaque psoriasis.

The 2010 guidelines from South Africa made treatment recommendations for plaque psoriasis of varying severity, although without specific recommendations for difficult-to -treat anatomic areas or in pediatric, geriatric, or pregnant patients. The 2014 guideline on biologics from Saudi Arabia included recommendations for the use of these agents in patients with plaque psoriasis, including in difficult-to-treat anatomic areas (e.g., nails, scalp, palmoplantar areas, and genital or intertriginous areas) and in pediatric patients (TNF inhibitors only), but provided no recommendations for pregnant or geriatric patients.

\section{Discussion}

There is an urgent unmet need for new clinical guidelines on the management of patients with plaque psoriasis in Africa and the Middle East. Our literature search demonstrated a paucity of published studies and guidelines from the region, with only 10 articles archived in the PubMed database during the previous 12 years. In general, the two sets of guidelines published during this period are mostly consistent with those from North America and Europe, ${ }^{15-19}$ but they do not adequately address the treatment of plaque psoriasis in difficult-to-treat anatomic areas or in pediatric, geriatric, or pregnant patients. Furthermore, these two guidelines (one from South Africa and one from Saudi Arabia) do not take into account the regional variations in socioeconomic and climatic factors that are evident within Africa and the Middle East and so their applicability to other countries may be limited. In addition to the lack of region-specific clinical guidelines, we also found that contemporary epidemiologic studies and studies investigating other disease characteristics, such as quality-of-life indices, comorbidities, and the overall impact of difficult-to-treat disease, are also unavailable. It should be noted that regionspecific studies and guidelines on the prevalence and management of psoriatic arthritis are also very sparse and yet very important given the severe and irreversible damage that can occur to the joints of patients and the lifelong disability that these complications can lead to. ${ }^{29,30}$

Overall, providing physicians in Africa and the Middle East with comprehensive, up-to-date, and region-specific guidelines on the various manifestations of plaque psoriasis and its comorbidities (e.g., depression, cardiovascular disease, and metabolic syndrome) should help to improve outcomes both for patients and for health care systems. Region-specific studies on the epidemiology, burden of disease, and safety and effectiveness of newer pharmacotherapies are also needed. Obviously, it must be considered that the geographic region comprising "Africa and the Middle East" is very large and includes extremely diverse societies, and therefore any new guidelines may have a varying degree of relevance to the specific socioeconomic and cultural circumstances present within each locale. The most applicable, and hence effective, guidelines may therefore be those that are developed at 
Table 3 Guidelines on the Management of Patients with Plaque Psoriasis in Africa and the Middle East Published from January 2008 to March 2020

\begin{tabular}{|l|l|l|}
\hline Patient Population & $\mathbf{2 0 I 0 ~ G u i d e l i n e s ~ f r o m ~ S o u t h ~ A f r i c a ~}{ }^{26}$ & $\mathbf{2 0 I 4}$ Guidelines on Biologics from Saudi Arabia \\
\hline General & $\begin{array}{l}\text { Mild-to-moderate disease (<5\% body surface area): topical } \\
\text { treatments (e.g., corticosteroids, coal tar, dithranol, } \\
\text { tazarotene, vitamin D analogs) } \\
\text { Moderate-to-severe disease ( } \geq 10 \% \text { body surface area): } \\
\text { systemic immunosuppressants (e.g., acitretin, cyclosporine, } \\
\text { methotrexate) and phototherapy (e.g., UVB, PUVA, 308 nm } \\
\text { excimer laser) } \\
\text { Severe disease (PASI score } \geq 10): \text { biologics (e.g., TNF } \\
\text { inhibitors, IL-I2/IL-23 inhibitors, alefacept) }\end{array}$ & $\begin{array}{l}\text { Yes, but only in patients who have failed, cannot } \\
\text { tolerate, or have a contraindication to topical therapy } \\
\text { and } \geq I \text { systemic treatment }\end{array}$ \\
\hline $\begin{array}{l}\text { Difficult-to-treat } \\
\text { anatomic areas }\end{array}$ & $\begin{array}{l}\text { Not specified } \\
\text { Pregnant women }\end{array}$ Not specified & $\begin{array}{l}\text { Yes (nails, scalp, palmoplantar areas, and genital or } \\
\text { intertriginous areas) }\end{array}$ \\
\hline Pediatric & Not specified & Not specified \\
\hline Geriatric & Not specified & Yes (TNF inhibitors only) \\
\hline
\end{tabular}

Note: Marketing of alefacept was discontinued in 2011.

Abbreviations: IL, interleukin; PASI, Psoriasis Area and Severity Index; PUVA, psoralen + ultraviolet light A; TNF, tumor necrosis factor; UVB, ultraviolet light B.

a national level. Additional tailoring of national guidelines to fit local circumstances may also be required in order to optimize the uptake of their recommendations. The first step in the development of new guidelines appropriate for African and Middle Eastern countries is to acknowledge the unmet needs and we believe the results of our literature search highlight the lack of regional evidence available for national societies to base recommendations upon. Additional funding will, of course, be required to support the studies necessary to generate such evidence and this remains a challenge that can probably only be addressed at a national level. Hopefully, the relevant clinical societies in African and Middle Eastern countries will, over time, have the opportunity to share insights with one another and collaborate on the bestpractice protocols most appropriate for the types of health care system present in their countries. It may take some time for such relationships to become established, but similar networks in Asian and European regions may serve as useful models for how supra-national organizations can contribute to the evolution of health care services within countries.

Our study has some limitations. Firstly, the PubMed database was the sole source of the publications identified by the literature search and it is possible that other relevant studies may not have been archived in this database but in others instead. Secondly, the literature search only considered publications from January 2008 to March 2020, although this may also be regarded as a strength of the study because only relatively recent publications were included and guidelines should be regularly updated.

\section{Conclusion}

There is an urgent unmet need for new clinical guidelines on the management of patients with plaque psoriasis in Africa and the Middle East, as well as research studies to provide evidence upon which their recommendations can be based. These studies and guidelines should help to improve the treatment strategies undertaken by physicians in the region and hopefully contribute to national governments recognizing plaque psoriasis as a debilitating and disabling disease that requires long-term management.

\section{Abbreviation}

TNF, tumor necrosis factor.

\section{Acknowledgments}

The authors wish to thank Dr Fahad M. Al Saif (King Saud University College of Medicine, King Saud Medical City, Saudi Arabia) for his contribution to the abstract and oral presentation/ePoster that preceded this article and which was presented at the American Academy of Dermatologists annual meeting in Washington D.C. in March, 2019. Medical writing support was provided by David Wateridge, PhD, of Engage Scientific Solutions and was funded by Pfizer. 


\section{Author Contributions}

All authors contributed to the conception and design of the literature search, as well as the interpretation of its findings. All authors critically revised the manuscript, approved the final version prior to submission, and agreed to be accountable for all aspects of the work.

\section{Funding}

There is no funding to report.

\section{Disclosure}

MS declares receiving advisory board and speaker honoraria and research grants from Celgene, Eli Lilly, Galderma, Janssen, LEO Pharma, Novartis, and Pfizer. AFA declares receiving consulting fees and serving on speakers bureau for Abbvie, Celgene, Eli Lilly, Janssen, LEO Pharma, Newbridge, Novartis, and Pfizer. HMA and MFSG are employees of Pfizer and hold stock or stock options with Pfizer. MHES declares receiving consulting fees from Abbvie, Janssen, and Novartis, and serving on speakers bureau for Abbvie, Janssen, LEO Pharma, and Novartis. The authors report no other conflicts of interest in this work.

\section{References}

1. Nestle FO, Kaplan DH, Barker J. Psoriasis. N Engl J Med. 2009;361 (5):496-509. doi:10.1056/NEJMra0804595

2. Boehncke WH, Schön MP. Psoriasis. Lancet. 2015;386 (9997):983-994. doi:10.1016/S0140-6736(14)61909-7

3. Gelfand JM, Feldman SR, Stern RS, Thomas J, Rolstad T, Margolis DJ. Determinants of quality of life in patients with psoriasis: a study from the US population. $J$ Am Acad Dermatol. 2004;51:704-708. doi:10.1016/j.jaad.2004.04.014

4. Horn EJ, Fox KM, Patel V, Chiou CF, Dann F, Lebwohl M. Association of patient-reported psoriasis severity with income and employment. J Am Acad Dermatol. 2007;57:963-971. doi:10.1016/j. jaad.2007.07.023

5. Vanderpuye-Orgle J, Zhao Y, Lu J, et al. Evaluating the economic burden of psoriasis in the United States. $J$ Am Acad Dermatol. 2015;72(6):961-967.e5. doi:10.1016/j.jaad.2015.02.1099

6. Feldman SR, Zhao Y, Shi L, Tran MH. Economic and comorbidity burden among patients with moderate-to-severe psoriasis. $J$ Manag Care Spec Pharm. 2015;21(10):874-888. doi:10.18553/jmcp.2015. 21.10 .874

7. Griffiths CEM, Jo SJ, Naldi L, et al. A multidimensional assessment of the burden of psoriasis: results from a multinational dermatologis and patient survey. Br J Dermatol. 2018;179(1):173-181. doi:10. 1111/bjd. 16332

8. Al Hammadi A, Al-Sheikh A, Ammoury A, et al. Experience and challenges for biologic use in the treatment of moderate-to-severe psoriasis in Africa and the Middle East region. J Dermatolog Treat. 2017;28(2):129-135.

9. Hartshorne ST. Dermatological disorders in Johannesburg, South Africa. Clin Exp Dermatol. 2003;28(6):661-665. doi:10.1046/ j.1365-2230.2003.01417.x

10. Shelleh HH, Al-Hatiti HS. Pattern of skin diseases in a hospital in southwestern Saudi Arabia. Saudi Med J. 2004;25(4):507-510.
11. Alakloby OM. Pattern of skin diseases in Eastern Saudi Arabia. Saudi Med J. 2005;26(10):1607-1610.

12. Gelfand JM, Weinstein R, Porter SB, Neimann AL, Berlin JA, Margolis DJ. Prevalence and treatment of psoriasis in the United Kingdom: a population-based study. Arch Dermatol. 2005;141 (12):1537-1541. doi:10.1001/archderm.141.12.1537

13. Augustin M, Glaeske G, Schäfer I, Rustenbach SJ, Hoer A, Radtke MA. Processes of psoriasis health care in Germany-longterm analysis of data from the statutory health insurances. $J$ Dtsch Dermatol Ges. 2012;10(9):648-655. doi:10.1111/j.1610-0387.2012. 07893.x

14. Egeberg A, Skov L, Gislason GH, Thyssen JP, Mallbris L. Incidence and prevalence of psoriasis in Denmark. Acta Derm Venereol. 2017;97(7):808-812. doi:10.2340/00015555-2672

15. Menter A, Gottlieb A, Feldman SR, et al. Guidelines of care for the management of psoriasis and psoriatic arthritis: section 1. Overview of psoriasis and guidelines of care for the treatment of psoriasis with biologics. J Am Acad Dermatol. 2008;58(5):826-850. doi:10.1016/j. jaad.2008.02.039

16. Menter A, Korman NJ, Elmets CA, et al. Guidelines of care for the management of psoriasis and psoriatic arthritis: section 3. Guidelines of care for the management and treatment of psoriasis with topical therapies. J Am Acad Dermatol. 2009;60(4):643-659. doi:10.1016/j. jaad.2008.12.032

17. Menter A, Korman NJ, Elmets CA, et al. Guidelines of care for the management of psoriasis and psoriatic arthritis: section 4. Guidelines of care for the management and treatment of psoriasis with traditional systemic agents. J Am Acad Dermatol. 2009;61(3):451-485. doi:10.1016/j.jaad.2009.03.027

18. Menter A, Korman NJ, Elmets CA, et al. Guidelines of care for the management of psoriasis and psoriatic arthritis: section 5. Guidelines of care for the treatment of psoriasis with phototherapy and photochemotherapy. J Am Acad Dermatol. 2010;62(1):114-135. doi:10.1016/j.jaad.2009.08.026

19. Pathirana D, Ormerod AD, Saiag P, et al. European S3-guidelines on the systemic treatment of psoriasis vulgaris. J Eur Acad Dermatol Venereol. 2009;23(Suppl 2):1-70. doi:10.1111/j.14683083.2009.03389.x

20. Al-Mutairi N, Al-Farag S, Al-Mutairi A, Al-Shiltawy M. Comorbidities associated with psoriasis: an experience from the Middle East. J Dermatol. 2010;37(2):146-155. doi:10.1111/j.13468138.2009.00777.x

21. Al-Mutairi N, Al-Haddad A. Targeted phototherapy using $308 \mathrm{~nm}$ Xecl monochromatic excimer laser for psoriasis at difficult to treat sites. Lasers Med Sci. 2013;28(4):1119-1124. doi:10.1007/s10103012-1210-4

22. Kassi K, Djeha D, Gbery IP, Kouame K, Sangaré A. Psoriasis in elderly patients in the Côte d'Ivoire: socio-demographic, clinical, and therapeutic aspects, and follow-up. Int J Dermatol. 2016;55(2):e8386. doi:10.1111/ijd.13138

23. Bulur I, Erdogan HK, Aksu AE, Karapınar T, Saracoglu ZN. The efficacy and safety of phototherapy in geriatric patients: a retrospective study. An Bras Dermatol. 2018;93(1):33-38. doi:10.1590/abd1806-4841.20185468

24. Abdulghani M, Al Sheik A, Alkhawajah M, et al. Management of psoriasis in Africa and the Middle East: a review of current opinion, practice and opportunities for improvement. J Int Med Res. 2011;39 (5):1573-1588. doi:10.1177/147323001103900501

25. Tavakolpour S, Rahimzadeh G. New insights into the management of patients with autoimmune diseases or inflammatory disorders during pregnancy. Scand J Immunol. 2016;84(3):146-149. doi:10.1111/ sji. 12453

26. Raboobee N, Aboobaker J, Jordaan HF, et al. Guideline on the management of psoriasis in South Africa. S Afr Med J. 2010;100(4 Pt 2):257-282. doi:10.7196/SAMJ.4015 
27. Hamadah IR, Al Raddadi AA, Bahamdan KA, et al. Saudi practical guidelines on biologic treatment of psoriasis. J Dermatolog Treat. 2015;26(3):223-229. doi:10.3109/09546634.2014.946882

28. Avitan-Hersh E, Erisson S, Bergman R, Solt I. Generalized pustular psoriasis of pregnancy [article in Hebrew]. Harefuah. 2012;151 (10):555-557, 606.

29. Usenbo A, Kramer V, Young T, Musekiwa A. Prevalence of arthritis in Africa: a systematic review and meta-analysis. PLoS One. 2015;10 (8):e0133858. doi:10.1371/journal.pone.0133858
30. Bedaiwi M, Al-Homood IA, El-Garf A, et al. Disease burden and treatment challenges of psoriatic arthritis in Africa and the Middle East. Rheumatol Int. 2019;39(8):1321-1329. doi:10.1007/s00296019-04319-3

\section{Publish your work in this journal}

Psoriasis: Targets and Therapy is international, peer-reviewed, open access journal focusing on psoriasis, nail psoriasis, psoriatic arthritis and related conditions, identification of therapeutic targets and the optimal use of integrated treatment interventions to achieve improved outcomes and quality of life. Visit http://www.dovepress. com/testimonials.php to read real quotes from published authors. 